\title{
Research cooperation with Bulgaria: Polyester Polyols from Waste PET Bottles for Polyurethane Rigid Foams
}

\author{
Roseta Evtimova, Yordanka Lozeva, Karl-Heinz Schmidt, Michael Wotzka, Peter Wagner, Gerhard Behrendt
}

\section{Introduction}

The increasing number of bottles made of polyethylene terephthalate (PET) or polyester copolymers with various glycols (e. g. PET-N) or carboxylic acids (e. g. PET-G) of various colours and forms make new paths of recycling after their use essential to the benefit of the environment. The sorting of bottles into fractions according to colour and their re-use is a common practice today. This process leads to non-coloured flakes but also to a mixed coloured fraction which is presently not used and usage is not foreseen. This paper describes a process to produce polyols for polyurethanes from the mixed coloured fraction after sorting out the transparent, non-coulored bottles. Into this process a second waste material is introduced originating from the production of the PET for bottles or fibres, being an oligoester condensate (OEK). The present state-of-the-art is to extract the noncoloured part of the PET-bottles from a mixture by various sorting techniques forming two fractions of which the translucent, non-coloured fraction is re-used mainly to produce bottles again ("bottle-to-bottle process"). The coloured fraction constitutes at present about some 50.000 t/a in Germany and it is not further processed to new materials but mainly shipped for carpet production. Further, during the PET condensation process a condensate is formed consisting of oligomeric terephthalates, mainly bis-(2-hydroxyethyl)terephthalate (HET), and some glycols (OEK), at present sent to an incinerator. OEK from the polycondensation process to form PET contains further varying amounts of glycols, mainly ethylene glycol, and some higher oligocondensates. The ethylene glycol content may range between 3 parts by weight and 35 parts by weight [1]. The reesterification of PET with glycols of different origin is well known [2-4] as is the esterification of dimethyl terephthalat (DMT) with an excess of glycols to produce polymeric diols having hydroxyl numbers $(\mathrm{OHZ})$ in the range of 420 to $90 \mathrm{mg} \mathrm{KOH/g}$. Several attempts have been made to increase the reaction rate of the reesterification process by catalysts of various origin generally employing organometallic catalysts of group B metals or germanium or antimony [5-8] or by applying higher pressure [9]. Another approach to use the PET wastes is to produce unsaturated polyester resins from them by re-esterification and condensation with maleic acid [10].

This paper describes a modified process to produce polyester polyols from PET wastes derived from the "bottle fraction residue" of the German Dual System
(DSD) [11] employing a waste oligoester condensate of the polyesterification process with the addition of some glycols of longer chain and occasional modification with further dicarboxylic acids to produce polyester polyols of a broad range of properties which are further reacted to form polyurethane or polyisocyanurate rigid foams for insulation, construction materials, or coatings.

\section{Materials and methods}

PET wastes were obtained from the DKR GmbH, Köln, Germany, a subsidiary of the DSD AG, Germany. The material was obtained as flakes of a diameter between $5 \mathrm{~mm}$ and $25 \mathrm{~mm}$ depending on the batch received. The quality of the flakes depended on the origin and the separation process having a PET content between 87 and $98 \%$ by weight. The contamination generally consisted of other plastics including ABS and PVC or rubber and additionally metals, esp. iron, steel, or aluminium parts, and some inorganic material like sand. The average composition of the flakes in the period of 1999 to 2001 is given in table 1 .

\begin{tabular}{|c|c|c|c|}
\hline Material of density range & amount $(\%$ b & y weight) & Anticipated material \\
\hline & $1999-2000$ & 2001 & \\
\hline Coarse material (screened) & $\begin{array}{r}7,3 \\
6,2 \\
11,2\end{array}$ & 0,2 & metals, paper \\
\hline $\begin{array}{l}\text { density }<1,0 \mathrm{~g} / \mathrm{cm}^{3} \\
\text { density } 1,0-1,2 \mathrm{~g} / \mathrm{cm}^{3} \\
\text { density } 1,2-1,35 \mathrm{~g} / \mathrm{cm}^{3} \\
\text { density }>1,35 \mathrm{~g} / \mathrm{cm}^{3}\end{array}$ & $\begin{array}{r}6,2 \\
11,2 \\
71,9 \\
0,9 \\
\end{array}$ & $\begin{array}{r}0,3 \\
2,0 \\
94,7 \\
2,6 \\
\end{array}$ & \begin{tabular}{|l|} 
PE, PP \\
PS, ABS \\
PET \\
PVC, filled ABS
\end{tabular} \\
\hline Contamination & 2,5 & 0,2 & sand \\
\hline
\end{tabular}

Tab. 1: Composition of PET-flake batches according to density

The oligocondensates were obtained in form of solids or slurries from Trevira AG, Guben, Germany. The composition of the OEK varies in a rather broad range with respect to the following constituents (determined by GPC and GC-MS):

$40-60 \%$ by weight terephthalic acid of which about $1 \%$ by weight is free,

$5-20 \%$ by weight bonded ethylene glycol,

$1-33 \%$ by weight free ethylene glycol,

1 - $5 \%$ by weight bonded diethylene glycol,

$1-5 \%$ by weight free diethylene glycol,

$0,2-2 \%$ by weight long chain glycols,

$0,3-1 \%$ by weight organometallic compounds.

The oligocondensates were either used as received or stripped at $130^{\circ} \mathrm{C}$ and 2 mbar prior to use from most of the ethylene glycol and homogenized this way. By this pretreatment the content of ethylene glycol was 
adjusted to $0,5 \%$ by weight. The organometallic compounds were not influenced by the treatment. Diethylene glycol (DEG) was obtained from Biesterfeld $\mathrm{GmbH}$ in $200 \mathrm{~kg}$ drums, adipic acid was a gift of the BASF AG. Poly(ethylene glycol) of molecular weight 200 or 400 (PEG 200, PEG 400) were samples provided by the Bayer AG which is gratefully acknowledged.

The reactions were run in two different batch sizes:

\subsection{Reaction in lab scale}

A four necked six liter flask was equipped with condenser, momentum controlled stirrer, temperature control by resistance thermometer coupled with the heating bath, and nitrogen inlet. First, the calculated amount of pretreated oligocondensate and any other glycol were introduced into the flask and both heated to about $180^{\circ} \mathrm{C}$. To this mixture the PET flakes were added while nitrogen was purged in and dissolved. After dissolution and rising the temperature to $200^{\circ} \mathrm{C}$ any additional carboxylic acid was added. The mixture was heated for the predetermined time at the temperature choosen while any volatiles (water, glycol, and side products) were distilled off and collected for GC-MS analysis. After the reaction was over (shown by no further volatiles appearing) the temperature was reduced to about $130^{\circ} \mathrm{C}$ and samples taken to determine the acid numbers, $\mathrm{OHZ}$, and viscosities.

\subsection{Reaction in technical scale}

A 100 I stainless steel jacketed reactor with demister, condenser, stirrer, nitrogen inlet, and feed equipped with a bottom valve and temperature control via an oil heater with control unit was fed with the necessary amount of oligocondensate and glycols. With stirring the mixture was heated to $180^{\circ} \mathrm{C}$ and any volatiles (mainly residual water) removed via the condenser. At this temperature the PET flakes were added and dissolved while purging with nitrogen and rising the temperature to $200^{\circ} \mathrm{C}$. Any further volatiles were removed by the condenser and outlet. After complete addition, any further additives were added. The temperature was adjusted to the reaction temperature and kept for the desired time while any volatiles are removed by the condenser and outlet. After completion of the reaction the temperature is gradually lowered to $150^{\circ} \mathrm{C}$ and the reaction product removed by the bottom valve via a metal filter into the storage containers.

\subsection{Determination of parameters}

The viscosity was determined at $25^{\circ} \mathrm{C}$ by means of a ball viscometer according to Höppler (MWM Radebeul), the acid number according to the DIN standard 53402 by titration with $0,25 \mathrm{M}$ potassium hydroxide solution in ethanol, the hydroxyl number according to the DIN standard 53240 by heating with a mixture of acetic anhydride in pyridine for one hour and titrating excess acetic acid after hydrolysis by $0.5 \mathrm{M}$ potassium hydroxide solution in ethanol.

\subsection{Foaming}

Two standard formulations were used:

The polyurethane rigid foam formulation used was

0,1 equivalent of polyol,

$0.9 \mathrm{~g}$ of water,

$0.1 \mathrm{~g}$ of silicone stabilizer Goldschmidt TEGOSTAB ${ }^{\circledR}$ B8433,

$0.25 \mathrm{~g}$ tris-(dimethylaminopropyl)hexahydro-s-triazine (Polycat ${ }^{\circledR}$ NP40) as a catalyst

to form an A-component. This was thoroughly mixed. To this A-component

0.2 equivalents of crude methylene-bis-(4-phenylisocyanate) (Lupranat ${ }^{\circledR}$ M 20 A of BASF AG)

were added and the mixture stirred for $10 \mathrm{sec}$ in a card board beaker of $500 \mathrm{ml}$ volume. The foam rise was followed by the Foamat ${ }^{\circledR} 20$ to determine characteristic times and rising properties.

For polyisocyanurate foams, a similar procedure was used. In this case only the amount of polyisocyanate used was increased to 0.6 equivalents of Lupranat ${ }^{\circledR}$ M20A giving an isocyanate index of 300 .

\subsection{Film formation}

As an example of polyol usage, films as a model of coatings were prepared. Into a beaker 0.5 equivalents of the polyol were mixed with $2,5 \mathrm{~g}$ of a synthetic sodium silicate as a moisture capture and 0.5 equivalents of Lupranat ${ }^{\circledR}$ M20A. The ingredients were thoroughly mixed for 20 seconds using a high speed stirrer of 6000 $\mathrm{min}^{-1}$ and degassed in vacuum for two minutes. The mixture was poured onto a silicone release paper, distributed by knife coating and hardened for $60 \mathrm{~min}$ at $80^{\circ} \mathrm{C}$ in the Labdryer. After hardening, the film was peeled off and left for one week at room temperature before mechanical testing. Stability tests were performed on 30 to $80 \mathrm{~mm}$ specimens in a Soxhlet extractor with $120 \mathrm{ml}$ n-decane at boiling conditions. The n-decane was afterwards subjected either directly to GC-MS (HewlettPackard GC 5890, MS 5970) or after concentration to a volume of $20 \mathrm{ml}$ under normal pressure using a $50 \mathrm{~cm}$ Vigreux column.

\subsection{Determination of physical properties}

Mechanical properties of films were tested by stress strain experiments using the Kogel film testing machine $20 \mathrm{~N}$ with a velocity of $2,5 \mathrm{~N} / \mathrm{min}$ program. The stress strain curves were stored and the tensile strength and elongation at certain proportions and at break were determined. DMA was performed using a Netzsch 204 A dynamic mechanical analyzer from room temperature to $240^{\circ} \mathrm{C}$. Relaxation spectra were obtained by a Myrenne torsion pendulum in a temperature range of 25 to $250^{\circ} \mathrm{C}$ with a heating rate of $1 \mathrm{~K} / \mathrm{min}$. Kinetic experiments were performed on a Rheostress 300 (Haake) using an 
oscillation mode at fixed temperatures. Foams were tested for dimensional stability according to DIN standards using a temperature chamber with air ventilation at 80 or $100^{\circ} \mathrm{C}$ for 24 hours using specimens of $50 \times 50 \times 50 \mathrm{~mm}$. Mechanical properties were determined using a Zwick Universalprüfmaschine for compressive strength. The temperature of deformation was tested on $20 \times 20 \times 150 \mathrm{~mm}$ bars in a sixfold Martens furnace with $20 \mathrm{~g}$ load on the outer end to give a contact after $6 \mathrm{~mm}$ deflection.

\section{Results}

\subsection{Synthesis of polyester polyols from oligocondensate and PET waste}

The OEK used for these experiments were wastes from fibre PET production accumulated in the heat exchanger and consisting mainly of bis-(2-hydroxy-ethyl)terephthalate, its dimer ethylene-bis-(2-hydroxyethyl terephthalic ester), $13 \%$ by weight ethylene glycol, and $0,43 \%$ by weight of a mixture of organometallic compounds of Ti and Ge. The OEK was mixed as described with different amounts of PET from the bottle fraction (coloured bottles) with $95 \%$ by weight PET and minor impurities mainly of PVC (metals, sand, and rubber particles were extracted by three times washing). The reaction conditions of several runs as well as the properties of the resulting polyester diols are presented in table 2 .

\begin{tabular}{|l|r|r|r|r|r|r|}
\hline Material/Run & \multicolumn{1}{|c|}{$2-10$} & \multicolumn{1}{|c|}{$2-90$} & $2-137$ & $2-12$ & $2-15$ & $2-26$ \\
\hline PET (\% by weight) & 53,8 & 43,3 & 52,6 & 60,6 & 49,0 & 52,0 \\
\hline OEK (\% by weight) & 3,2 & 15,5 & 15,8 & 39,4 & 51,0 & 48,0 \\
\hline DEG (\% by weight) & 43,0 & 0 & 15,8 & 0 & 0 & 0 \\
\hline DPG (\% by weight) & 0 & 41,2 & 15,8 & 0 & 0 & 0 \\
\hline Reaction conditions: & & & & & & \\
Temperature ("C) & 220 & 240 & 240 & 220 & 220 & 220 \\
Time (hours) & 6 & 6 & 12 & 2 & 3 & 3.5 \\
\hline Properties: & 279 & 419 & 265 & 228 & 189 & 253 \\
OHZ (mg KOH $/ \mathrm{g}$ ) & 2 & 1 & 2,5 & 3 & 4 & 3 \\
Acid number (mg KOH/g) & 13,300 & 19,000 & 40,000 & 68,000 & 165,000 & 22,000 \\
Viscosity at 25 $2{ }^{\circ} \mathrm{C}(\mathrm{mPas})$ & 0,12 & 0,1 & 0,2 & 0,2 & 0.2 \\
Water content (\%) & 0,06 & 0,12 &
\end{tabular}

Tab. 2: Aromatic polyester polyols based on PET and OEK

By using only these two waste components, previously incinerated in a specialized incineration plant, useful polyester diols for polyurethane production may be obtained. From the polyester diols, films having hardness Shore $\mathrm{D}$ beyond 60 were prepared which might be used as an in-liner in waste water chanel repair. The elongation at break is within the typical range of 5 to $15 \%$ depending on the molecular weight of the polyester diols. The longer chains exhibiting a somewhat softer appearance and being more flexible in spite of the multifunctional crosslinker Lupranat ${ }^{\circledR}$ M20A having an average functionality of about 4.0. Similarly, films were obtained with pure methylene bis(4-phenyl isocyanate) (MDl) despite the high reactivity of the polyols and consequently extremely short reaction times. The films were surprisingly not more flexible so that some crystallization is assumed to be the reason (table 3 ). The relative hardness of these films leads to rather good values of abrasion resistance and allows them to fit into the property spectrum of in-liners.

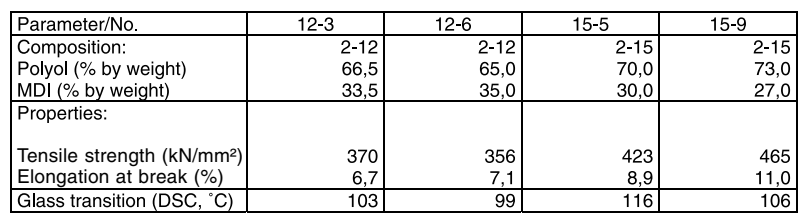

Tab. 3: Properties of films obtained from aromatic polyester polyols

Foams were produced only from the polyester polyols of lower viscosity so that only two polyols with high hydroxyl number are left. The high reactivity made a reduction of the amount of catalyst to $0.175 \mathrm{~g}$ in the formulation necessary also in this case. The properties of the foams are shown in table 8 . It can be seen that rigid polyurethane foams from these polyester polyols exhibit a very good dimensional stability when using this special formulation, i. e. water to produce carbon dioxide as a foaming agent and tris-(dimethylaminopropyl)hexahydro-s-triazine as a catalyst which is ordinarily used for trimerization of isocyanate groups but shows a very good effect when used in this combination of water as a blowing agent and polyester polyols as the main constituent of the A component [12].

\subsection{Polyester polyols from PET, oligoester and glycols}

To reduce the viscosity by simultaneously keeping the good properties in balance several attempts were made with glycols to substitute part of the oligoester. Examples of this series of polyols obtained by such a process are shown in table 4 . It is obvious from these

\begin{tabular}{|c|c|c|c|c|c|c|}
\hline Material/Run & $4-90$ & $4-106$ & $4-127$ & $4-137$ & 4-145 & 4-152 \\
\hline PET (\% by weight) & 40,9 & 57,7 & 58,5 & 51,9 & 47,2 & 48,7 \\
\hline OEK (\% by weight) & 14,5 & 2,9 & 17,6 & 15,6 & 2,8 & 15,2 \\
\hline $\begin{array}{l}\text { Glycols: (\% by weight) } \\
\text { DEG } \\
\text { TEG }\end{array}$ & & 33,6 & 17,5 & 14,5 & 46,2 & $\begin{array}{r}32,5 \\
3,6\end{array}$ \\
\hline PEG 200 & 5,8 & 5,8 & & & 3,8 & \\
\hline $\begin{array}{l}\text { DPG } \\
\text { PPG } 400\end{array}$ & 38,8 & & 6,4 & $\begin{array}{r}14,5 \\
3,5\end{array}$ & & \\
\hline Properties: & & & & & & \\
\hline $\mathrm{OHZ}(\mathrm{mg} \mathrm{KOH} / \mathrm{g})$ & 410 & 314 & 326 & 254 & 170 & 203 \\
\hline Acid number (mg KOH/g) & & & 4 & & & 1,5 \\
\hline Viscosity $\left(25^{\circ} \mathrm{C}\right)$ (mPas) & 56,000 & 32,100 & & 42,000 & 71,300 & 30,600 \\
\hline Reaction conditions: & & & & & & \\
\hline Temperature $\left({ }^{\circ} \mathrm{C}\right)$ & $\begin{array}{r}240 \\
6\end{array}$ & 240 & $\begin{array}{r}240 \\
12\end{array}$ & $\begin{array}{r}240 \\
12\end{array}$ & $\begin{array}{r}240 \\
10\end{array}$ & 240 \\
\hline
\end{tabular}

Tab. 4: Aromatic polyester polyols with various glycols

data that by reducing the amount of oligoester with respect to the overall formulation polyester polyols with much lower viscosities even in the low hydroxyl number range are obtained. By comparing the mechanical properties of the PUR rigid foams of the main types of polyols it is shown that the most advantageous glycol of this series is diethylene glycol which results in properties close to those produced by means of the polyols under 3.1 when their hydroxyl number exceeds $200 \mathrm{mg} \mathrm{KOH} / \mathrm{g}$. It turns out that diethylene glycol is most suitable in combination with the other two raw materials leading to polyester polyols of viscosities between 11.000 and $37.000 \mathrm{mPas}\left(20^{\circ} \mathrm{C}\right)$. The viscosity depends to a high degree on the amount of volatiles distilled off. In some cases, some of the lower glycols have been collectively derived from the reaction mixture resulting in increased viscosity but lower hydroxyl numbers (2-137compared to 2-10). The acid number of the polyester polyols increased with increasing reaction time at constant temperature hinting to some side reactions occuring on prolonged heating. The addition of tetraethylene glycol 


\begin{tabular}{|l|r|r|r|r|r|}
\hline Materials/Run & \multicolumn{1}{|c|}{$6-06$} & \multicolumn{1}{|c|}{$6-11$} & $6-14$ & $6-17$ & \multicolumn{1}{|c|}{$6-21$} \\
\hline PET (\% by weight) & 38.3 & 40.8 & 43.1 & 45.2 & 50,0 \\
\hline OEK (\% by weight) & 41.4 & 40.7 & 37.9 & 35.5 & 33.3 \\
\hline DEG (\% by weight) & 20.3 & 18.5 & 19.0 & 19.3 & 16,7 \\
\hline Properties: & & & & & \\
OHZ (mg KOH/g) & 326 & 297 & 303 & 289 & 271 \\
Acid number (mg KOH/g) & 1.5 & 1.7 & 1.5 & 2 & 2 \\
Viscosity (25 $\mathrm{C}$ ) (mPas) & 11,600 & 14,700 & 15,900 & 19,400 & 36,500 \\
\hline
\end{tabular}

Tab. 5: Polyester polyols from PET, OEK, and diethylene glycol with low hydroxyl numbers

to the reaction mixtures does not favour any of the properties when used in combination with other glycols (diethylene or dipropylene glycol) as shown with the extremely high visosities (4-152 and P 4-24).

In case of the lower hydroxyl numbers the mechanical properties and especially the dimensional stability are reduced since the crosslinking by the polyisocyanate does not equalize the low overall crosslink density as expressed by the average molecular weight between crosslinks.

The polyester polyols with hydroxyl numbers lower than $320 \mathrm{mg} \mathrm{KOH} / \mathrm{g}$ are used with higher indices to produce polyurethane polyisocyanurates which give parameters of higher quality with respect to mechanical and flammability properties (see 3.5 and table 8 ).

The polyester polyols with hydroxyl numbers lower than $200 \mathrm{mg} \mathrm{KOH} / \mathrm{g}$ are used as additives to polyurethane soft foam formulations which rise their comfort factor in typical moulded polyether foams when used with a percentage up to $15 \%$ by weight. The lower limit of polyester polyols of this type with useful properties is in the range of a hydroxyl number of about $120 \mathrm{mg} \mathrm{KOH} / \mathrm{g}$. By the method described it is possible to produce polyester polyols being characterized by hydroxyl numbers as low as $70 \mathrm{mg} \mathrm{KOH} / \mathrm{g}$ but they exhibit viscosities in the range up to $350,000 \mathrm{mPas}\left(25^{\circ} \mathrm{C}\right)$ which make them applicable only as an additive to formulations with low viscosity polyols and being compatible with them (forming a homogeneous polyol component for two component applications).

\subsection{Polyester polyols from PET, oligoester, phthalic acid, and glycols}

In another series of polyester polyol synthesis part of the oligoester was substituted by phthalic acid as phthalic anhydride. Terephthalates tend to crystallize because of the fitting of both the terephthalic acid molecule and the respective glycol, the best example is PET itself. By introducing smaller amounts of phthalic acid into the polyester chain the ability to crystallize is drastically reduced and, furthermore, the viscosity of the polyester polyols is reduced (see table 6). The modification of the

\begin{tabular}{|c|c|c|c|c|c|c|}
\hline Materials/Run & P4-13 & P4-14 & P4-19 & P4-24 & P4-18 & P4-33 \\
\hline $\begin{array}{l}\text { Phthalic anhydride (\% by } \\
\text { weight) }\end{array}$ & 24.8 & 24.8 & 25.9 & 23.5 & 27.6 & 25.5 \\
\hline OEK (\% by weight) & 34.2 & 32.0 & 35.6 & 32.3 & 37.9 & 34.5 \\
\hline $\begin{array}{l}\text { DEG (\% by weight) } \\
\text { TEG } \% \text { by weight) }\end{array}$ & 41.0 & 43.2 & 38.5 & $\begin{array}{r}34.9 \\
9.3 \\
\end{array}$ & 34,5 & 40.0 \\
\hline $\begin{array}{l}\text { Reaction conditions: } \\
\text { Temperature ( } \mathrm{(} \mathrm{C} \text { ) } \\
\text { Time (hours) }\end{array}$ & $\begin{array}{r}220 \\
6 \\
\end{array}$ & $\begin{array}{r}220 \\
5\end{array}$ & $\begin{array}{r}220 \\
7\end{array}$ & $\begin{array}{r}220 \\
9 \\
\end{array}$ & $\begin{array}{r}220 \\
5\end{array}$ & $\begin{array}{r}220 \\
6 \\
\end{array}$ \\
\hline $\begin{array}{l}\text { Properties: } \\
\mathrm{OHZ}(\mathrm{mg} \mathrm{KOH} / \mathrm{q})\end{array}$ & 244 & 281 & 250 & 241 & 209 & 344 \\
\hline Acid number $(\mathrm{mg} \mathrm{KOH} / \mathrm{g})$ & & 0.3 & 1.0 & & & 0.6 \\
\hline Viscosity $\left(25^{\circ} \mathrm{C}\right)$ (mPas) & 19,200 & 14,100 & 15,500 & 18,700 & 59,200 & 7,800 \\
\hline
\end{tabular}

Tab. 6: Polyester polyols from PET, OEK, phthalic acid, and glycols polyester polyols made from PET, OEK, phthalic anhydride as well as an additional glycol or glycols results in polyols suitable both for rigid foams and coating applications. The synthesis was directed both to rigid foam application polyols with hydroxyl numbers in the range of $350 \mathrm{mg} \mathrm{KOH/g}$ (P4-33) and to coating application with hydroxyl numbers in the range of hydroxyl numbers around $230 \mathrm{mg} \mathrm{KOH} / \mathrm{g}$ (P4-24, table 6). The introduction of phthalic acid moieties into the chain does not reduce the flammability compared to the polyester polyols with only terephthalic acid but reduces the dimensional stability of the rigid foams produced from them (see 3.5). With respect to the coatings formulations there is an improvement in the elongation at break but a reduction of the plateau region of the storage modulus limiting the temperature range of application.

\subsection{Polyester polyols from PET, oligoester, adipic acid, and glycols}

Another approach to obtain polyester polyols with lower viscosity was to modify them with aliphatic dicarboxylic acids such as adipic, sebacic, or azelaic acid to make them more suitable for two component formulations. Adipic acid is known to produce in combination with certain glycols low melting and non-crystallizing polyester polyols (e. g. to be used for microcellular elastomers) and in combination with phthalic acid and any polyvalent hydroxyl compound like pentaerythrol polyester polyols suitable as basis for varnishes.

\begin{tabular}{|c|c|c|c|c|c|}
\hline Material/Run & $4-30$ & $4-8$ & $4-37$ & 4-39 & $4-44$ \\
\hline PET (\% by weight) & 42.5 & 0 & 42.8 & 54.0 & 39.5 \\
\hline OEK (\% by weight) & 2.6 & 44.9 & 2.5 & 3.2 & 2.4 \\
\hline Adipic acid (\% by weight) & 23.0 & 25.5 & 22.9 & 15.8 & 28.5 \\
\hline $\mathrm{DEG}(\%$ by weight) & 31.9 & 0 & 31.8 & 27.0 & 19.7 \\
\hline DPG (\% by weight) & 0 & 0 & 0 & 0 & 9.9 \\
\hline TEG (\% by weight) & 0 & 29.6 & 0 & 0 & 0 \\
\hline $\begin{array}{l}\text { Conditions: } \\
\text { Temperature }\left({ }^{\circ} \mathrm{C}\right)\end{array}$ & 220 & 240 & 220 & 220 & 240 \\
\hline Time (hours) & 5 & 3 & 4 & 5 & 10 \\
\hline Properties: & & & & & \\
\hline $\mathrm{OHZ}(\mathrm{mg} \mathrm{KOH} / \mathrm{g})$ & 172 & 130 & 184 & 169 & 198 \\
\hline Acid number $(\mathrm{mg} \mathrm{KOH} / \mathrm{g})$ & 0.8 & 3.3 & 0.7 & 1,2 & 1.8 \\
\hline Viscosity $\left(25^{\circ} \mathrm{C}\right)(\mathrm{mPas})$ & 11,700 & 2,880 & 16,100 & 15,600 & 15,800 \\
\hline
\end{tabular}

Tab. 7: Polyester polyols from PET, OEK, adipic acid, and glycols

In this series of syntheses the reduction of viscosity was attempted without a substantial loss of the valuable properties of the aromatic polyester polyols with respect to high dimensional stability and high flame retardancy in rigid foam formulations. In the series of hydroxyl numbers of ca. $180 \mathrm{mg} \mathrm{KOH} / \mathrm{g}$ and various proportions of terephthalic to adipic acid it is seen that the viscosity reduces with increasing amount of adipic acid as expected leading to a value of only $3.000 \mathrm{mPas}\left(25^{\circ} \mathrm{C}\right)$ with $25 \%$ by weight adipic acid. In the series with hydroxyl numbers in the range of $180 \mathrm{mg} \mathrm{KOH} / \mathrm{g}$ the viscosity was reduced from $71.000 \mathrm{mPas}$ (4-145) to $11.700 \mathrm{mPas}\left(25^{\circ} \mathrm{C}\right)$ at $23 \%$ by weight of adipic acid [13]. The dimensional stability of rigid foams produced from these lower viscosity copolyester polyols is but reduced to about $100^{\circ} \mathrm{C}$. Thus, the main field of application of this type of polyester polyols is in coatings formulations in the Shore A hardness range beyond 90 .

Thus, polyester polyols with higher content of aliphatic dicarboxylic acids are reacted with diphenylmethane-4,4'diisocyanate (MDI) or crude MDI like Lupranat ${ }^{\circledR}$ M20A to 
give coatings, e. g. to be used in coating of concrete floorings aiming at a Shore A hardness of 93. The composition of such coatings at the relative hardness of Shore $A$ beyond 90 leads to rather good values of abrasion resistance and allows them to fit into the property spectrum of sealants or in-liners of waste water tubes.

\subsection{Polyurethane foams made of the polyester polyols}

\begin{tabular}{|c|c|c|c|c|c|}
\hline Materials/No. & F12-2 & F26-5 & F10-3 & F90-1 & F137-4 \\
\hline $\begin{array}{l}\text { Polyester polyol } \\
2-12(\mathrm{~g}) \\
2-26(\mathrm{~g}) \\
2-10(\mathrm{~g}) \\
2-90(\mathrm{~g}) \\
2-137(\mathrm{~g}) \\
\end{array}$ & $\begin{array}{r}24.6 \\
0 \\
0 \\
0 \\
0 \\
\end{array}$ & $\begin{array}{r}0 \\
24.8 \\
0 \\
0 \\
0 \\
\end{array}$ & $\begin{array}{r}20.1 \\
0 \\
0 \\
\end{array}$ & $\begin{array}{r}0 \\
0 \\
0 \\
13.4 \\
0 \\
\end{array}$ & $\begin{array}{r}0 \\
0 \\
0 \\
0 \\
21.1\end{array}$ \\
\hline Lupranat $(\mathrm{M} 20 \mathrm{~A}(\mathrm{~g})$ & 27.0 & 27.0 & 27.0 & 27.0 & 27.0 \\
\hline $\begin{array}{l}\text { Properties: } \\
\text { Density }\left(\mathrm{g} / \mathrm{dm}^{3}\right) \\
\text { Compressive strength } \\
\left(\mathrm{N} / \mathrm{mm}^{2}\right) \\
\text { Dimensional stability at } \\
120^{\circ} \mathrm{C}(\%)\end{array}$ & $\begin{array}{r}42.1 \\
3.65 \\
+1.4\end{array}$ & 4.02 & 2.54 & 4.21 & 3.78 \\
\hline $\begin{array}{l}\text { Flammability according to } \\
\text { ASTM } 1692 \text { (burning } \\
\text { distance } \mathrm{mm} \text { ) }\end{array}$ & 5 & 5 & 8 & 6 & 6 \\
\hline
\end{tabular}

Tab. 8: Polyurethane rigid foams from polyester polyols based on PET, $O E K$, and some glycols

Polyurethane rigid foams were produced from all the polyester polyols synthesized using a standard formulation. In this standard formulation only the polyester polyol is used as a single polyol component while crosslinking the polymer structure only by the polyvalent polyisocyanate. Additional crosslinking may arise from biurete formation resulting from the reaction of the ureas formed by the reaction of isocyanate groups and water and another isocyanate group. Rigid foams were tested for compressive strength and dimensional stability and in some cases for flammability.

PUR rigid foams could be produced only from those PET based polyester polyols (see 3.2 ) having lower viscosity and higher hydroxyl numbers. If the viscosity exceeded $35.000 \mathrm{mPas}$ it was necessary to prepare the premixes at somewhat higher temperatures and add the polyisocyanate to this mixture. This leads to higher reactivity and made a reduction of the amount of catalyst to $0.175 \mathrm{~g}$ in the formulation necessary. The properties of some of the foams produced are shown in table 8 . The property values show that rigid polyurethane foams from these aromatic polyester polyols exhibit a very good dimensional stability at $120^{\circ} \mathrm{C}$ when using this specially developed formulation and employing only these PET based polyols, water to produce carbon dioxide as a foaming agent and tris-(dimethylaminopropyl)hexahydro-s-triazine as a catalyst which is typically used for trimerization of isocyanate groups but shows a very good effect when used in this combination of water as a blowing agent and polyester diols as the main constituent of the A component [14]. The foams made according to these formulations show that even at a comparatively low isocyanate index of 75 the dimensional stability at $120^{\circ} \mathrm{C}$ is below an deterioration of $3 \%$ in each direction thus showing a high thermal stability to be achieved by means of the polyester diols. To this value adds the good mechanical stability at a density of about $40 \mathrm{~g} / \mathrm{dm}^{3}$ which is generally better than the predicted values [15]. The problem with polyols of this type is the high viscosity which gives rise to a limited field of application.
The mechanical properties of the PUR rigid foams made of polyols of series 3.2 show rather good mechanical properties in spite of a brittleness sometimes to observe which originates from residual ethylene glycol and short chained terephthalates. Considering all observed properties of the foams leads to the conclusion that the most advantageous glycol in the transesterification is diethylene glycol which results in highest property levels. The comparison of foam properties of the polyols produced according to method 3.1 and 3.2 shows that the polyols of type 3.2 give results in properties close to those produced by means of the polyols of the type according to 3.1 when both their hydroxyl numbers exceed $360 \mathrm{mg} \mathrm{KOH} / \mathrm{g}$. Polyols exhibiting lower hydroxyl numbers, i. e. a higher content of terephthalic acid (polyols 2-90 or 4-90), fit as well into this frame when the hydroxyl number is beyond $320 \mathrm{mg} \mathrm{KOH} / \mathrm{g}$. Changing the glycols, i. e. substitute the diethylene glycol by higher ethylene glycol homologues or by dipropylene glycol or higher homologues always leads to reduced property levels at comparable hydroxyl numbers. The substitution of terephthalic acid by any other acid has a similar effect. Larger amounts of adipic acid condensed into the polyester chain reduce the thermal stability as shown by the reduced dimensional stability. Phthalic acid as well reduces the dimensional stability to a lower extent but keeps the compressive strength. Lower hydroxyl numbers lead to a loss in mechanical properties and especially the dimensional stability since the crosslinking by the polyisocyanate does not equalize the functionality of 2 in these polyester polyols.

Generally, to produce suitable rigid foams the hydroxyl number of the polyester polyols has to exceed $360 \mathrm{mg}$ $\mathrm{KOH} / \mathrm{g}$ even at high terephthalic acid content. When the hydroxyl number or the amount of terephthalic acid is lowered the dimensional stability are reduced. The introduction of aliphatic dicarboxylic acids (adipic acid) or phthalic acid leads to a reduction both of dimensional stability (in case of adipic acid based polyols it is lower than $80^{\circ} \mathrm{C}$ ) and flammability. While in these cases of lower hydroxyl numbers or adipic acid adition the brittleness of the foams is reduced and they exhibit some elasticity the mechanical properties and especially the dimensional stability are reduced since the crosslinking by the polyisocyanate leads to a rather high average molecular weight between crosslinks $\left(\mathrm{M}_{\mathrm{n}}\right)$ compared to typical polyether based rigid polyurethane foams. In this structure the polymer chains are more flexible and this flexibility increases the segment mobility of the structural units.

The polyester polyols with hydroxyl numbers lower than $300 \mathrm{mg} \mathrm{KOH} / \mathrm{g}$ are used with higher isocyanate indices and appropriate catalysts to produce polyurethane polyisocyanurates [16] which give parameters of higher quality with respect to mechanical and flammability properties (table 9). Frequently, a hydroxyl number of aromatic polyester polyols of $240 \mathrm{mg} \mathrm{KOH} / \mathrm{g}$ is used in this case with isocyanate indices up to 900 . The reduction in flammability is but an optimum mostly depending on the overall structure of the polymer. 


\begin{tabular}{|c|c|c|c|c|c|}
\hline Materials/No. & F14-6 & F17-3 & F24-6 & F145-5 & F137-4 \\
\hline $\begin{array}{l}\text { Polyester polyol } \\
6-14(\mathrm{~g}) \\
6-17(\mathrm{~g}) \\
\mathrm{P} 4-24(\mathrm{~g}) \\
4-145(\mathrm{~g}) \\
4-137(\mathrm{~g})\end{array}$ & $\begin{array}{r}18.6 \\
0 \\
0 \\
0 \\
0 \\
\end{array}$ & $\begin{array}{r}0 \\
19.4 \\
0 \\
0 \\
0 \\
\end{array}$ & $\begin{array}{r}0 \\
0 \\
13.4 \\
0 \\
0 \\
\end{array}$ & $\begin{array}{r}0 \\
0 \\
0 \\
33.0 \\
0 \\
\end{array}$ & $\begin{array}{r}0 \\
0 \\
0 \\
0 \\
22.1 \\
\end{array}$ \\
\hline $\begin{array}{l}\text { Lupranat } ₫ M 20 \mathrm{~A}(\mathrm{~g}) \\
\text { Isocyanate Index }\end{array}$ & $\begin{array}{r}81.0 \\
400 \\
\end{array}$ & $\begin{array}{r}81.0 \\
400 \\
\end{array}$ & $\begin{array}{r}67.5 \\
300 \\
\end{array}$ & $\begin{array}{r}94.5 \\
500 \\
\end{array}$ & $\begin{array}{r}81.0 \\
400 \\
\end{array}$ \\
\hline $\begin{array}{l}\text { Properties: } \\
\text { Density }\left(\mathrm{g} / \mathrm{dm}^{3}\right) \\
\text { Compressive strength } \\
\left(\mathrm{N} / \mathrm{mm}^{2}\right) \\
\text { Dimensional stability at } \\
120^{\circ} \mathrm{C}(\%) \\
140^{\circ} \mathrm{C}(\%) \\
\text { Burn length following } \\
\text { ATSM } 1692(\mathrm{~mm})\end{array}$ & $\begin{array}{r}44.1 \\
4.76 \\
-0.2 \\
+1.2\end{array}$ & $\begin{array}{r}45.7 \\
4.88 \\
+0.4 \\
+1.4\end{array}$ & $\begin{array}{r}-0.5 \\
+1.0\end{array}$ & $\begin{array}{l}56.7 \\
5.34 \\
+0.2 \\
+2.1\end{array}$ & $\begin{array}{l}46.7 \\
4.23\end{array}$ \\
\hline
\end{tabular}

Tab. 9: Polyisocyanurate foams based on low hydroxyl number polyester polyols

According to the tests used in this investigation the improvement in flammability according to the test procedure ASTM 1692 beyond an index of 400 could not be proved.

The polyester polyols with hydroxyl numbers lower than $200 \mathrm{mg} \mathrm{KOH} / \mathrm{g}$ are used as additives to polyurethane soft foam formulations which rises their comfort factor in typical moulded polyether foams when used with a percentage up to $15 \%$ by weight. The lower limit of polyester polyols of this type with useful properties is in the range of a hydroxyl number of about $120 \mathrm{mg} \mathrm{KOH} / \mathrm{g}$.

\section{Discussion of results}

Based on two wastes - an industrial residue OEK and a consumer waste PET mixed colour flakes - aromatic polyester polyols of various properties could be produced by variation of the ratio of these two components and the addition of other components like glycols and/ or other dicarboxylic acids. In several experimental series the effect of these components on the properties both of the polyester polyols and rigid polyurethane foams derived from them was investigated. By using only PET waste and OEK residue it is possible to obtain liquid products showing very high viscosity and a tendency to recrystallize. Therefore, it is useful to add at least one glycol which can be choosen from a broad series of ethylene glycols or propylene glycols up to molecular weights of $2000 \mathrm{~g} / \mathrm{mol}$ or copolyethers of both structural units as being prepared by ionic polymerization of ethylene oxide and propylene oxid either as statistical or block copolyethers. It turned out that diethylene glycol is the most suitable glycol to be used in these transesterifications but the addition of some other, i. e. longer chained glycols, may in some cases add further advantages to the polyester polyols derived especially with respect to their viscosity or to avoid recrystallization to keep the viscosity of the polyols constant on storage.

The reduction of the hydroxyl number of the polyols generally leads to high viscous products. To compensate for this effect it seemed an opportunity to use glycols of longer molecular chains with molecular weights up to $1000 \mathrm{~g} / \mathrm{mol}$. While the viscosity of the polyol could be adjusted to values between 10,000 and $15,000 \mathrm{mPas}$ the rigid foams produced from these polyols using a standard formulation showed a reduced dimensional stability which in turn could be compensated for only by the addition of high functional polyethers or amino polyethers. On the other hand, such polyester polyols are useful as basic polyols to produce polyisocyanurate foams with isocyanate indexes up to 400 .

Introducing a second or third dicarboxylic acid like adipic or phthalic acid into the polyester polyols leads as well to a reduction in viscosity and in recrystallization. While these effect is desirable both acids used as structural components in the polyester polyol chains again lead as well to an adverse effect on the properties of the rigid foams. In general, the incorporation of both dicarboxylic acids reduces the dimensional stability of rigid foams. Additionally, with higher proportions of adipic acid in the chain the flame retardancy is reduced. Such polyester polyols are suitable in applications like polyisocyanurate foams or coatings or sealants where flame retardancy is mainly adjusted either by the isocyanuric acid rings or by the addition of solid flame retardants.

Aromatic polyester polyols with a high terephthalic acid content and diethylene glycol as the main glycol component lead with specially designed polyurethane formulations to rigid polyurethane foams with exceptional high dimensional stability up to $145^{\circ} \mathrm{C}$ and simultaneously good mechanical properties. Thus, the rigid foams prepared on this way may be used in such cases where typically the more costly polyisocyanurate foams are used.

Further applicational areas of the aromatic polyester polyols are coatings and sealants when the viscosity at hydroxyl numbers of 200 to $240 \mathrm{mg} \mathrm{KOH} / \mathrm{g}$ is in the range up to $20.000 \mathrm{mPas}\left(25^{\circ} \mathrm{C}\right)$ or additives to soft block foam production in amounts up to $15 \%$ by weight when the hydroxyl number is as low as 90 to $120 \mathrm{mg} \mathrm{KOH/g}$. To increase the flame retardant activity of such polyester polyols dispersions with certain solid flame retardants are obtained by adjusting the polyol structure to become self-stabilizing [17]. Furthermore, binder systems based on certain types of these polyester polyols had been developed to form composite materials with natural products [18].

\section{Literature}

[1] A. Lobeda, H. Becker, G. Behrendt, Aromatische Polyesteralkohole aus Oligokondensaten, unveröffentlichte Ergebnisse, Berlin, 1994

[2] U. R. Vaidya, V. M. Nadkarni, Polyester Polyols for Polyurethanes from PET Waste, in J. Appl. Polym. Sci. 35, 775785 (1988)

[3] U. R. Vaidya, V. M. Nadkarni, Polyester polyols from PET waste: effect of glycol type on kinetics of polyesterification in J. Appl. Polym. Sci. 38, 1179-1190 (1991)

[4] S. Baglia,. W. T. Wong, Depolymerization of polyethylene terephthalate recycled from postconsumer softdrink bottles, J. Polym. Sci, Part A 27, 2071-2082 (1989)

[5] DE-AS 2.238.109 (1973) to Upjohn Co.

[6] DE-OS 2.557.172 (1976) to Bridgestone Tire Co.

[7] DE-OS 2.711.145 (1978) to Bayer AG

[8] DE-OS 2.834.431 (1980) to Th. Goldschmidt AG 
[9] J. Y. Chen, C. F. Ou, Y. C. Hu, C. C. Lin, Depolymerization of polyethylene terephthalate resin under pressure, J. Appl. Polym. Sci. 42, 1501-1507 (1991)

[10] 5U. R. Vaidya, V. M. Nadkarni, Unsaturated polyester resins from PET waste: 1 . Synthesis and characterization, in Ind. Engng. Chem. Res. 26, 194-198 (1987)

[11] G. Behrendt, A. Lobeda, M. Pohl, Verfahren zur Herstellung von Polyesteralkoholen sowie Polyesteralkohole, DE Anm. 19817538.8 vom 16. 4. 1998, PCT WO

[12] G. Behrendt, M. Pohl, Verfahren zur Herstellung von Polyurethanen, DE-OS 19817539 (16.04.1998)

[13] G. Behrendt, M. Pohl, Polyesterpolyole mit niedriger Viskosität, DE-Anm. 19915128.8 vom 25.03.1999

[14] G. Behrendt, M. Pohl, Polyurethanmassen und Verfahren zu ihrer Herstellung, DE-Anm. 19852151.0 vom 04.11.1998

[15] R. K. Traeger, J. Cellular Plast. 3, 405 (1967)

[16] M. Pohl, G. Behrendt, Polyisocyanurat-Formstoffe und Verfahren zu ihrer Herstellung, DE-Anm. 19915126.1 vom 25.03.1999

[17] G. Behrendt, M. Pohl, H.-D. Hunger, Neue Polyester-Polymerpolyole fuir Polyurethane, DE-Anm. 19915125.3 vom 25.03.1999

[18] M. Pohl, U. Lehrack, J. Volk, G. Behrendt, Verbundmaterial und Verfahren zu seiner Herstellung, DE-PS 19817541 vom 16.04.1998, erteilt 18.02.2002

\section{Acknowledgement}

The authors are grateful for financial support of the studies by the Deutscher Akademischer Austauschdienst (DAAD) and the International Bureau of the German Federal Ministry of Education (BMBF).

\section{Authors}

\section{Prof. Dr. Roseta Evtimova}

University of Chemical Technology and Metallurgy

Bul. KI. Ohridski 8, 1175 Sofia, Bulgaria

Telefon +3592681513

Dipl.-Ing. Yordanka Lozeva

University of Chemical Technology and Metallurgy

Bul. KI. Ohridski 8, 1175 Sofia, Bulgaria

Telefon +3592681513

\section{Dr. Peter Wagner}

GKT Gräfenthaler Kunststofftechnik GmbH

Coburger Straße 56-58, 98743 Gräfenthal, Germany

Telefon +4936703 85-0

E-Mail: info@gkt.de

\section{Dipl.-Ing. Karl-Heinz Schmidt}

Technische Fachhochschule Wildau

Fachbereich Ingenieurwesen/Wirtschaftsingenieurwesen

Telefon +493375 508-176

E-Mail: khschmid@igw.tfh-wildau.de

\section{Dipl.-Ing. Michael Wotzka}

CTA Anlagenbau GmbH

Julius-Pintsch-Ring 18, 15517 Fürstenwalde, Germany

Telefon +4933613621-0

E-Mail: cta_anlagenbau@t-online.de

\section{Prof. Dr. Gerhard Behrendt}

Technische Fachhochschule Wildau Fachbereich Ingenieurwesen/Wirtschaftsingenieurwesen Telefon +493375 508-591

E-Mail: behrendt@vt.tfh-wildau.de 